\title{
Impacto da integração regional sobre os fluxos mundiais de Investimento Direto Estrangeiro ${ }^{1}$
}

\author{
Carolina de Almeida Jorge ${ }^{2}$ \\ Marta Castilho ${ }^{3}$
}

\section{Resumo}

Os anos 1990 destacaram-se pelo avanço da "globalização", que consiste em uma nova fase de internacionalização das economias nacionais. Este processo é caracterizado por diversos fenômenos econômicos e políticos que aprofundaram a integração das economias nacionais à economia global. $\mathrm{O}$ crescimento dos fluxos mundiais de investimento direto estrangeiro e o avanço do regionalismo são dois destes fenômenos e estão interligados por diversas razões e mecanismos. O presente artigo pretende avaliar o impacto dos arranjos regionais de comércio sobre os fluxos mundiais de IDE baseado na hipótese de que os arranjos comerciais, tradicionalmente geradores de comércio, podem engendrar efeitos de criação e desvio de investimento. A fim de tornar possível tal análise, estimouse um modelo gravitacional para um painel de 71 países para o período 1990-2003. Foram utilizados diversos métodos de estimação, recomendados pela literatura recente, como os métodos de Poisson, "pooled cross-section" e de efeitos fixos. Os resultados apontam para a existência de uma relação positiva entre IDE e integração regional para a maioria dos acordos analisados, através de um aumento dos fluxos de IDE intrarregionais e da atratividade dos países membros de um acordo relativo a terceiros países. Os resultados, no entanto, mostram ainda algumas disparidades relevantes, resultantes dos diversos procedimentos de estimação e do tratamento dos dados empregados, o que sinaliza que, apesar do modelo gravitacional se mostrar um bom instrumento de análise, algumas questões metodológicas ainda continuam em aberto. Adotamos procedimentos distintos de estimação recomendados pela literatura recente referente aos modelos gravitacionais a partir dos quais se verificou a relação entre IDE e integração, embora os resultados tenham se mostrado muito heterogêneos, conforme o método utilizado.

Palavras-chave: Arranjos regionais de comércio; Investimento Direto Estrangeiro; Modelo gravitacional; Criação e desvio de investimento.

\section{Abstract}

\section{The effects of regional integration on the world foreign direct investment flows}

The so-called "globalization" process was an important feature of the global economy in the 90's. This process was characterized by several economic and political phenomena that deepened the integration of national economies to global economy. The growth of the world's foreign direct investment (FDI) flows and the advance of regionalism are two of these phenomena interrelated by

(1) Trabalho recebido em 17 de outubro de 2008 e aprovado em 30 de março de 2010. Agradecemos os comentários das Professoras Viviane Luporini (UFRJ) e Juliette Milgram (Universidad de Granada), assim como os de um parecerista anônimo, isentando-os de qualquer responsabilidade por eventuais incorreções remanescentes.

(2) Economista da Eletrobrás, Rio de Janeiro, RJ, Brasil. E-mail: carolina.jorge@eletrobras.com.

(3) Professora do Instituto de Economia da Universidade Federal do Rio de Janeiro, Rio de Janeiro, RJ, Brasil. E-mail: castilho@ie.ufrj.br.

Economia e Sociedade, Campinas, v. 20, n. 2 (42), p. 365-395, ago. 2011. 
many reasons and mechanisms. This present paper aims to evaluate the impact of regional trading agreements over the world's FDI flows, based on the hypothesis that the trading arrangements, which traditionally generate trade, can also have investment creation and diversion effects. A gravity model was estimated for an unbalanced panel constituted by 71 countries for the period 1990-2003. We compared the results from several estimation methods recommended by recent literature like Poisson, pooled cross-section and fixed effects methods. Our results show that trade arrangements tend to increase FDI due to the raise of intra-regional investment and also to the increase of member countries' attractiveness. Nevertheless, even if the gravity model has shown to be adapted for the analysis of the relationship between FDI and regionalization, some methodological issues remain opened.

Keywords: Regional trading arrangements, Foreign Direct Investment, Gravity equation, Investment creation and diversion.

JEL F21, F15.

\section{Introdução}

A década de 1990 apresentou características marcantes no que concerne ao avanço do processo de internacionalização das economias nacionais, processo, este, denominado "globalização" e caracterizado pela maior relação entre as economias nacionais e a economia global, através de maiores fluxos de mercadorias e de fatores, sobretudo de capital. Os fluxos de IDE (Investimento Direto Estrangeiro) e do comércio aumentaram de forma expressiva e contínua. Ao mesmo tempo, observou-se uma forte proliferação de acordos regionais movimento que ficou conhecido como "novo regionalismo" (em contraste com o movimento de regionalização da década de 60).

Ampla literatura dedica-se à análise das relações existentes entre comércio e regionalismo. Porém, as análises disponíveis sobre IDE são raras, apesar do interesse e da importância do tema.

O aumento dos fluxos de IDE mundiais a partir da década de 90 foi surpreendente. Sua taxa de crescimento superou as taxas de crescimento do PIB e das exportações: no período compreendido entre 1986 e 1999, as taxas de crescimento ao ano foram de, respectivamente, $17,7 \%, 2,5 \%$ e $5,6 \%$, segundo Blonigen (2006). Além disso, os fluxos de IDE sofreram mudanças qualitativas, em especial no que diz respeito ao seu direcionamento - com o crescimento da importância dos países em desenvolvimento enquanto países hospedeiros - e ao aumento da participação dos investimentos no setor de serviços, em detrimento do setor industrial.

Neste mesmo período houve um avanço na formação de acordos regionais. Segundo a WTO (2007), dos 330 acordos comerciais notificados aos órgãos multilaterais de comércio desde a criação do GATT, em 1947, até julho de 2005, 206 foram incluídos após a criação da OMC (Organização Mundial do Comércio) em janeiro de 1995. As mudanças nesses últimos também foram qualitativas, 
sobretudo no que se refere à composição dos acordos (participação de países com diferentes níveis de desenvolvimento) e à inclusão de novos temas (tais como investimentos, propriedade intelectual, serviços, cláusulas políticas, sociais e ambientais).

A concomitância de tais fatos sugere a existência de uma relação positiva entre IDE e regionalismo. Ainda assim, o aumento expressivo dos fluxos de IDE não foi generalizado a todos os acordos e a todos os países membros de um mesmo bloco comercial. Tais considerações instigam o interesse pelo estudo da conexão entre ambos.

Este artigo pretende avaliar em que medida a formação de acordos regionais contribuiu para o aumento dos fluxos mundiais de IDE a partir da análise empírica de tais fluxos para um amplo conjunto de países durante a década de 90 . Para isso, o artigo inicia-se com uma apresentação do panorama internacional na década de 90, a fim de mostrar, por um lado, a trajetória crescente do volume de IDE e sua distribuição regional e, por outro, a proliferação de acordos regionais. Em seguida, busca-se, na literatura teórica sobre IDE e também sobre as relações entre regionalismo e comércio, algumas explicações e ligações possíveis entre os dois fenômenos. Por fim, avalia-se empiricamente a relação entre os dois fenômenos através da estimação de uma equação gravitacional. Esta ferramenta é geralmente utilizada para a análise dos fluxos de comércio e, mais recentemente, para fluxos de investimento. Os resultados das diversas especificações testadas são apresentados e servem para avaliar não somente o fenômeno econômico em si mas também o uso deste instrumento no tratamento do tema em questão. A análise será realizada para um conjunto de 71 países no período compreendido entre 1990 e 2003.

\section{0 crescimento dos fluxos de IDE e a expansão do regionalismo na década de 1990}

O rápido crescimento dos fluxos de IDE teve início nos anos 80, intensificando-se, porém, durante a década de 90 , sobretudo na segunda metade, quando alcançou um aumento de mais de $30 \%$ a.a (Gráfico 1). Em termos reais, nas décadas de 80 e 90, o IDE mundial tem crescido em média 14\% a.a. Não obstante, na segunda metade dos anos 90, este aumento foi ainda maior, alcançando um crescimento real médio de 27\%. Este crescimento superou significativamente o dos fluxos de comércio, que, entre 1980 e 1999, foi de 3,4\% a.a. A disparidade na intensidade de crescimento do comércio e dos IDEs foi ainda maior na segunda metade da década de 90 , quando a taxa de crescimento dos fluxos de comércio foi de $6,2 \%$ a.a., o que equivalia a quase $1 / 5$ da taxa de crescimento dos fluxos mundiais de IDE. O crescimento dos IDEs mundiais foi tão grande que em 2000 seu valor equivalia a 25 vezes o valor de 1980 e 
praticamente a 7 vezes o valor de 1990 (de acordo com os dados da Unctad, citado por Castilho; Soares [2005], p. 7).

\section{Gráfico 1}

Fluxos de Investimento Direto Estrangeiro no período 1980-2005 (em bilhões correntes de US\$)

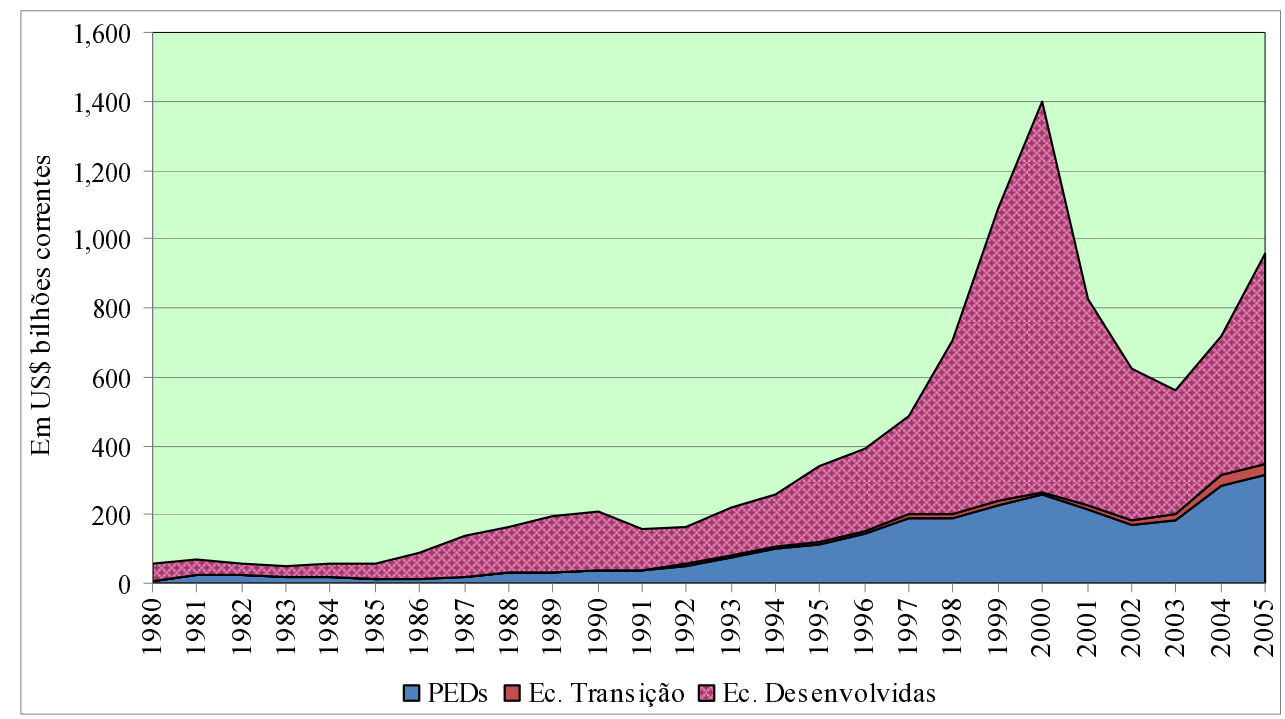

Fonte: WIR (2008).

Além do crescimento mencionado, os fluxos de IDE apresentaram algumas mutações em relação aos períodos anteriores. Um dos aspectos importantes foi o avanço das fusões e aquisições ( $F \& A$ ), fato, este, que pode ter, como veremos adiante, uma relação com o avanço da integração regional. No final dos anos 90, as F\&A majoritárias consistiam em quase 2/3 de todo o fluxo de IDE (Sarti, 2001). No período entre 1988 e 1995, as fusões e aquisições dobraram de valor, alcançando US\$229 bilhões.

Os países desenvolvidos mantiveram seu papel predominante como principais receptores de IDE durante a década de 90, sendo responsáveis por 70\% do total de influxos mundiais (a média para todo o período; ver Tabela 1). A União Europeia foi uma das principais regiões receptoras de IDE - sua importância nos influxos mundiais sugere que a integração econômica explica (ao menos, em parte) este fato.

No entanto, embora os países desenvolvidos tenham sido os grandes receptores de IDE, uma das características marcantes do crescimento recente dos fluxos mundiais foi a progressiva participação dos países em desenvolvimento (PED) (ver Tabela 1). Houve, na década de 1990, um crescimento sem precedentes de fluxos de IDE para esses países (Calderón; Loayza; Servén, 2004). 
Tais fluxos serviram como principal forma de financiamento externo, após 1994, para grande parte dos PEDs. Dentro deste grupo, a China e alguns países da Europa Central e do Leste destacaram-se pelo rápido aumento de estoque de IDE.

Os motivos para o crescimento do IDE na China estão relacionados ao forte crescimento daquela região e do fortalecimento de sua indústria. No que se refere à Europa Central e do Leste, os processos de privatização na região, assim como a recuperação econômica de alguns países, e o acesso à União Europeia são os principais fatores explicativos ${ }^{4}$.

Tabela 1

Fluxos mundiais de IDE por país receptor, 1990-2005

(em US\$ bilhões)

\begin{tabular}{l|r|r|r|r|c}
\hline & 1990 & 1995 & \multicolumn{1}{|c}{2000} & 2005 & Média 90-05 (\%) \\
\hline Total & 207.3 & 341.0 & 1398.2 & 958.7 & 100.0 \\
\hline Países Desenvolvidos & 172.1 & 221.0 & 1134.6 & 611.3 & 69.7 \\
\hline União Europeia & 97.3 & 131.9 & 698.1 & 498.4 & 43.6 \\
\hline EUA & 48.4 & 58.8 & 314.0 & 104.8 & 19.0 \\
\hline Países em Desenvolvimento & 35.1 & 116.0 & 256.6 & 316.4 & 28.6 \\
\hline Ásia e Pacífico & 22.7 & 80.1 & 148.4 & 210.0 & 17.0 \\
\hline China & 3.5 & 37.5 & 40.7 & 72.4 & 6.8 \\
\hline África & 2.8 & 5.7 & 9.7 & 29.5 & 1.9 \\
\hline Am. Latina e Caribe & 8.9 & 29.5 & 98.3 & 76.4 & 9.6 \\
\hline Argentina & 1.8 & 5.6 & 10.4 & 5.3 & 1.0 \\
\hline Brasil & 1.0 & 4.4 & 32.8 & 15.1 & 2.4 \\
\hline Chile & 0.7 & 3.0 & 4.9 & 7.0 & 0.7 \\
\hline México & 2.6 & 9.5 & 18.0 & 20.9 & 2.4 \\
\hline Ec. Transição & 0.1 & 4.1 & 7.0 & 31.0 & 1.7 \\
\hline Europa Central e do Leste & 0.8 & 14.4 & 21.1 & 42.2 & 2.7 \\
\hline Fon WIR (2008). & & & & & \\
\hline
\end{tabular}

Fonte: WIR (2008).

Por outro lado, a nova fase de internacionalização das economias nacionais dos anos 90 refletiu-se também no crescimento do número de acordos comerciais. Na realidade, este movimento é conhecido como "novo regionalismo" em contraste com a "onda" de regionalização dos anos 50/60. Para se ter uma ideia, conforme a OMC, ao final de 2002, 250 acordos tinham sido notificados ao GATT/OMC desde a criação do primeiro em 1948. Destes, apenas uma centena é anterior a 1990 (World Bank, 2000). Como se pode ver pelo Gráfico 2, quando se considera o número de acordos que estão efetivamente em vigor, verifica-se que a concentração dos mesmos no período recente é ainda maior.

(4) Há também outros fatores atrativos a considerar na região, como o acesso ao mercado, similaridades culturais, proximidade geográfica, estabilidade política, assim como mão de obra barata e qualificada (WIR, 1996). 
A atual onda de regionalismo apresentou características peculiares relativamente ao ciclo anterior, principalmente no que se refere à abrangência geográfica e em termos de temas. Em primeiro lugar, dos acordos mais antigos participavam apenas países do mesmo nível de desenvolvimento foi o caso da integração latino-americana ou europeia no período, diferentemente da fase recente, em que blocos são compostos por países desenvolvidos e em desenvolvimento. Atualmente, a maioria dos países, sejam eles industrializados ou países em desenvolvimento, são membros de (pelo menos) algum acordo de integração regional, sendo que muitos fazem parte de mais de um bloco (World Bank, 2000). Houve uma ampliação das disciplinas e temas cobertos pelos acordos, que passaram a ir além de assuntos puramente comerciais (como a queda de tarifas ou a extinção de quotas). Não só passaram a integrar temas como investimentos e serviços como também a englobar disciplinas referentes a temas não diretamente ligados ao comércio tais como propriedade intelectual, meio ambiente, cláusulas sociais, entre outros.

O movimento concomitante destes dois fenômenos já constitui, por si só, uma motivação para sua análise empírica. Porém, como veremos a seguir, a integração regional também pode estimular o crescimento dos fluxos de IDE de diversas formas e diferentes maneiras, segundo determinadas características, aumentando, assim, o interesse da presente análise.

Gráfico 2

Evolução do número de acordos regionais em vigor notificados à OMC, 1948-2005

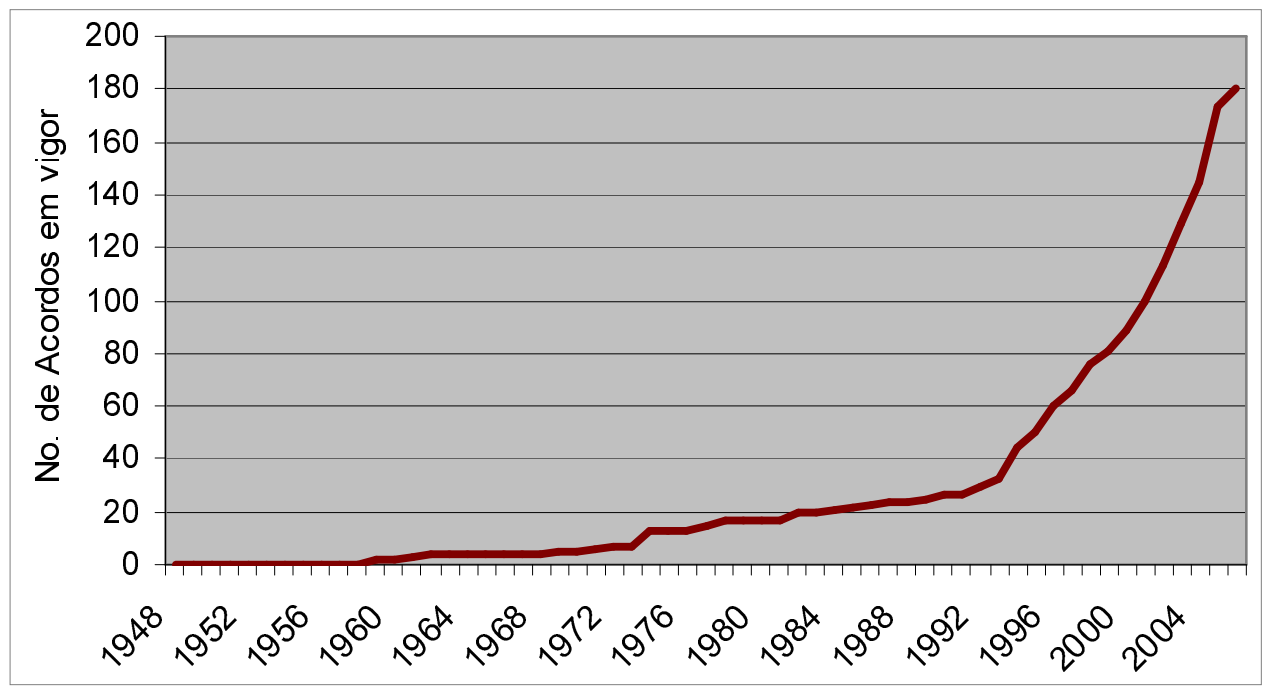

Fonte: WTO. 
Impacto da integração regional sobre os fluxos mundiais de Investimento Direto

\section{Referencial teórico: IDE e Integração}

Os mecanismos econômicos através dos quais a integração regional influencia os fluxos de IDE variam de acordo com a motivação e com o tipo de investimento realizado, sendo estes dois aspectos interligados.

\subsection{Motivações e tipos de IDE}

A teoria eclética de Dunning (1993) apud BID (2002), distingue quatro tipos de investimento segundo sua motivação. São eles: estratégias de marketseeking, resource-seeking, efficiency-seeking e asset-seeking. Quando o interesse do IDE consiste na exploração do mercado interno do país hospedeiro, tem-se a chamada estratégia de market-seeking. A segunda estratégia relaciona-se ao IDE que tem como objetivo explorar os recursos naturais disponíveis no país hospedeiro. A estratégia de efficiency-seeking refere-se ao investimento com finalidade de racionalizar a produção de forma a gerar economias de escala, especialização e de escopo (Dunning, 1988, 1994 apud Sarti, 2001, p. 184). Tal racionalização é obtida por meio da integração de diferentes filiais, conforme assinalado por Kosacoff e Porta (1997). Já o investimento do tipo asset-seeking consiste no IDE que tem como propósito a detenção de ativos que proporcionem à firma melhor capacidade competitiva. Pode ser representado pela fusão e aquisição de firmas estabelecidas, bem como pelo IDE com objetivo de incorporação de novas capacidades tecnológicas (Kosacoff; Porta, 1997).

Outra abordagem - não conflitante com a proposta de Dunning - propõe diferenciar os investimentos como vertical, horizontal e de bens diferenciados. O IDE vertical organiza-se de forma que cada etapa produtiva opere no país, que se beneficia de vantagens nos preços dos fatores utilizados intensivamente, sendo, portanto, sua existência associada à diferença de dotações dos fatores entre os países de origem e hospedeiros (Hejazi; Safarian, 1999). Neste tipo de IDE, investimento e comércio se complementam, podendo a filial produzir em um país de forma a se aproveitar de custos menores dos fatores e exportar o bem produzido para o país de origem, conforme afirmado por Brenton, Di Mauro e Lücke (1999). O IDE horizontal concerne às empresas que apresentam múltiplas unidades de produção, com cada unidade ofertando para os respectivos mercados locais, não havendo comércio entre elas (Markusen, 1984 apud Hejazi; Safarian, 1999). O objetivo consiste na obtenção de economias de escala provenientes das diversas

plantas. Além disso, conforme o BID (2002), o bem produzido em cada unidade é homogêneo. 
E, finalmente, há o IDE de bens diferenciados, que se distingue do último tipo essencialmente pelo fato de a produção final não ser direcionada somente para o mercado local mas também para o mercado externo (através das exportações). Nesse caso, a firma produz diferentes variedades de bens.

Estas duas abordagens são complementares. Os IDEs dos tipos efficiencyseeking e resource-seeking podem ser classificados como IDE vertical e, nestes dois casos, investimento e comércio se complementam. No primeiro tipo, a firma se especializa verticalmente de forma a explorar vantagens comparativas, aumentando o comércio intrafirma com o objetivo de reduzir custos. Já no caso do IDE do tipo resource-seeking, a firma investirá no país devido ao melhor acesso aos recursos naturais vigentes e exportará a produção para seu país de origem.

O IDE do tipo market-seeking é identificado como IDE horizontal ou até mesmo como IDE de bens diferenciados, visto que é caracterizado pelo interesse no mercado interno, não existindo comércio entre as filiais e a matriz. Já o tipo asset-seeking pode aparecer tanto nos investimentos do tipo vertical quanto horizontal, dependendo do interesse do investimento, ou seja, se está relacionado com o mercado local do país hospedeiro ou se envolve o mercado mundial, conforme detalhado na próxima seção.

\subsection{Integração comercial e IDE}

No quadro a seguir são sintetizados os efeitos da integração regional sobre os diversos tipos de IDE, ou seja, são avaliados os efeitos de criação e desvio de investimento. Para tal, são utilizados os conceitos de criação e desvio de comércio, inicialmente propostos por Viner (1959), para avaliar o impacto de processos de integração econômica sobre os fluxos de comércio. O termo criação de investimento, segundo Kindleberger (1996) apud Blomström e Kokko (1997, p. 6), refere-se à decisão, por parte das firmas que se situam fora da região de integração, de realizar investimento na mesma, diante da perda potencial de seu mercado exportador, ou seja, de sua clientela, que passa a compor a região de integração. A perda é explicada pelo fato de os clientes recorrerem aos fornecedores da região devido ao comércio, isento de tarifas. Portanto, os ganhos das empresas localizadas na região integrada podem levar a um aumento do número de firmas no bloco e à redução do número de firmas fora da região de integração. Isso significa um aumento do estoque de capital no interior do acordo de integração e uma redução do estoque de capital no restante dos países. Tais fatos são chamados, respectivamente, de criação de investimento e desvio de investimento. $\mathrm{O}$ desvio de investimento pode, então, ser resultante da incorporação do país investidor dentro do acordo regional. Assim, os membros do acordo tornam-se países hospedeiros mais atrativos do que os não membros (BID, 2002). 
O efeito da integração sobre o IDE pode se dar em direções contrárias, por meio de canais distintos (BID, 2002). A firma poderá ser incentivada a realizar IDE em função do mercado protegido, de modo a atendê-lo através da filial estrangeira, ou pode ser desestimulada a realizá-lo, uma vez que pode aumentar a concorrência.

No caso do IDE vertical, um dos objetivos da firma pode ser a busca de eficiência através da especialização vertical, de forma a explorar as vantagens comparativas dos países membros, aumentando o comércio intrafirma, dada a inexistência de tarifas no bloco comercial. Nesse caso, a criação de comércio leva à reestruturação produtiva regional, induzindo o IDE entre países do bloco (Blomström; Kokko, 1997). A outra motivação poderia estar relacionada ao melhor acesso a insumos (inclusive, de recursos naturais) mais baratos, incentivando o deslocamento de unidades produtivas dentro do bloco e a comercialização no seu país de origem, estimulado pelo livre comércio na região do acordo.

Estes IDEs são denominados, respectivamente, efficiency-seeking e resource-seeking. O primeiro proporciona o aumento de investimento direto tanto entre países membros quanto oriundo de países extrabloco em detrimento dos fluxos de IDE para os últimos. Quanto ao tipo resource-seeking, o livre comércio de insumos em um acordo comercial gera a criação de investimento entre países membros e desvio de investimento nos países extrabloco devido às melhores condições de acesso a mercados outorgadas aos países membros.

Quadro 1

Impacto da integração segundo tipo IDE

\begin{tabular}{|l|l|l|}
\hline Tipos IDE & Estratégias & \multicolumn{1}{|c|}{ Impacto Esperado Integração } \\
\hline \multirow{3}{*}{ Horizontal } & $\begin{array}{l}\text { Market-seeking } \\
\text { (IDE tariff-jumping) }\end{array}$ & $\begin{array}{l}\text { criação investimento bloco de países extra-bloco } \\
\text { desvio investimento países extra-bloco } \\
\text { aumento comércio entre países-membros em detrimento } \\
\text { IDE }\end{array}$ \\
\cline { 2 - 3 } & Asset-seeking & $\begin{array}{l}\text { criação investimento bloco de países extra-bloco } \\
\text { desvio investimento países extra-bloco }\end{array}$ \\
\hline \multirow{3}{*}{ Vertical } & Resource-seeking & $\begin{array}{l}\text { criação investimento intra-bloco } \\
\text { desvio investimento países extra-bloco }\end{array}$ \\
\cline { 2 - 4 } & Efficiency-seeking & $\begin{array}{l}\text { criação investimento entre países-membros e de extra-bloco } \\
\text { desvio investimento países extra-bloco }\end{array}$ \\
\cline { 2 - 4 } & Asset-seeking & $\begin{array}{l}\text { criação investimento intra-bloco e de países extra-bloco } \\
\text { desvio investimento países extra-bloco }\end{array}$ \\
\hline Bens & $\begin{array}{l}\text { (plataforma } \\
\text { exportação) }\end{array}$ & $\begin{array}{l}\text { criação investimento bloco de países extra-bloco } \\
\text { desvio investimento países extra-bloco }\end{array}$ \\
\hline
\end{tabular}

Fonte: Elaboração própria. 
O IDE do tipo asset-seeking com IDE vertical consiste na busca de ativos - sejam eles associados a menores custos ou à maior eficiência - com o objetivo de tornar as firmas mais competitivas. É o caso, por exemplo, do estabelecimento de filiais que criam uma rede internacional de unidades de uma mesma firma de modo a aproveitar as diferenças locais no que diz respeito à tecnologia, estendendo, assim, o conhecimento tecnológico por meio de um processo coordenado de aprendizado. Neste caso, é esperada a criação de investimento tanto em países membros quanto em países extrabloco.

Quanto ao IDE horizontal, um estímulo para sua efetivação seria a existência de barreiras comerciais de importação (tarifárias ou não tarifárias). Ao se constituírem em obstáculos ao comércio, elas incentivam o investimento direto da firma em um país do bloco comercial para explorar o mercado em questão e, uma vez fixada na região, passa a não incorrer em barreiras comerciais - este IDE é conhecido como "tariff-jumping". O efeito da integração sobre este tipo de IDE pode se dar em dois sentidos: o impacto pode ser positivo, ao aumentar a atratividade do IDE oriundo de países extrabloco (em detrimento destes últimos) devido à ampliação do mercado decorrente da ausência de tarifas entre países membros (criação de investimento no bloco e desvio de investimento em países extrabloco), porém, a ausência de tarifas pode elevar o comércio intrabloco em detrimento do IDE.

A estratégia de "tariff-jumping" ocorre quando a tarifa externa vigente no acordo de integração é elevada e os custos fixos da planta a ser instalada são baixos (Neary, 2001 apud Montout; Zitouna, 2005, p. 4).

O IDE, embora apresente um custo fixo considerável, proporciona retornos crescentes de escala e então o mercado maior torna-se mais atrativo para investimento relativamente ao menor (Jaumotte, 2004). Assim, a ampliação do mercado como implicação da Integração Regional permitirá um crescimento maior e mais intenso das firmas, como assinalado por Montout e Zitouna (2005).

O IDE também pode ser estimulado com o intuito de internalizar ativos específicos, dado o fato de não serem transacionados de modo eficiente pelo mercado (Blomström; Kokko, 1997), como o IDE do tipo asset-seeking horizontal. Neste caso, o acordo comercial pode também gerar criação de investimento proveniente de países extrabloco e desvio nos últimos, uma vez que o IDE pode ser estimulado pela melhor proteção do mercado, formado pelo acordo com relação aos demais países extrabloco, possibilitando a incorporação de maior parcela de mercado.

Por outro lado, a remoção de barreiras entre os países do bloco torna o ambiente mais competitivo e, de forma a gerir o novo ambiente, a firma pode decidir por fundir-se com os antigos concorrentes. Ao se tornar maior, a firma tem

(5) Ver BID (2002, p. 228). 
mais propensão a investir em $\mathrm{P} \& \mathrm{D}$ e marketing, possibilitando, dessa forma, a geração de novos ativos intangíveis e incentivando novos fluxos de IDE tanto dentro quanto fora da região (Blomström; Kokko, 1997).

Finalmente, com relação ao IDE de bens diferenciados, um exemplo consiste na firma transnacional que elege determinado país participante de um acordo comercial para produzir e vender não só para o próprio mercado como também para utilizá-lo como plataforma de exportação para os demais países membros do acordo. Este IDE é explicado pelo desejo da firma de um terceiro país não membro de se estabelecer em determinado país da região de integração, dada a redução das barreiras comerciais vigentes, de modo a atender os demais mercados integrantes através da exportação. É provável ainda que a firma busque se fixar no país membro cujos custos de produção sejam menores (Montout e Zitouna, 2005). Este fato, portanto, sugere que países membros se tornam relativamente mais atrativos que países extrabloco, refletindo-se na criação de investimento no bloco e desvio de investimento nos últimos.

\section{Efeitos dos acordos regionais de integração sobre os fluxos de Investimento Direto Estrangeiro}

Para se analisar os efeitos da integração regional sobre os fluxos de investimento direto estrangeiro estimamos uma equação gravitacional para um amplo painel de países durante a década de 90. Como visto, devido à multiplicidade de efeitos da integração sobre os IDEs, os impactos podem ser positivos ou negativos, dependendo se há criação ou desvio de investimento.

A presente seção é consagrada às estimações de tais efeitos. Porém, antes de analisarmos os resultados propriamente ditos, discutiremos as escolhas metodológicas realizadas e apresentaremos os dados utilizados.

\subsection{Metodologia}

A ferramenta utilizada para análise é o modelo gravitacional utilizado com frequência em análises empíricas de fluxos de comércio internacional. Sua aplicação a outros fluxos - notadamente de investimento - tem sido crescente. A aplicação de tal modelo em comércio internacional e outros fluxos econômicos (IDE, migração, turismo) reproduz a ideia, proveniente da teoria gravitacional da Física, segundo a qual o fluxo entre dois corpos resulta de forças de atração e repulsão. No caso do comércio, em sua versão mais simplificada ${ }^{6}$, as forças de atração consistem nos tamanhos dos países (participação no comércio mundial) e a força de repulsão, na distância geográfica (que determina os custos de transporte

(6) Ver Krugman (1995). 
das mercadorias). À equação original foram acrescentados diversos outros determinantes dos fluxos bilaterais de comércio?

No caso dos fluxos bilaterais de IDE, estes seriam determinados pelo tamanho dos dois países (PIB), por seu nível de renda (PIB per capita), pelos custos de transação diversos associados à distância entre os dois países, pelos custos associados ao isolamento, por fatores culturais e históricos (língua comum, existência de fronteira e ocorrência de relações coloniais), além dos acordos regionais.

O PIB do país influencia positivamente os fluxos de IDE, uma vez que mercados maiores são mais atrativos, enquanto a renda per capita, que reflete o nível de desenvolvimento do país, pode impactar positivamente ou negativamente. Se o IDE visa atender o mercado hospedeiro, o impacto esperado é positivo, uma vez que sinaliza maior poder de compra, ao passo que, se a finalidade é exportar para os demais países, buscará por custos menores de mão de obra e, consequentemente, o impacto esperado é negativo.

A distância pode exercer um impacto tanto positivo quanto negativo (Brenton; Di Mauro; Lücke, 1999). Os movimentos de IDE podem ser incentivados com o aumento da distância, dado o aumento dos custos de comércio. Neste sentido, o IDE apareceria como um substituto aos fluxos de comércio. No entanto, a distância pode afetar negativamente os fluxos de IDE à medida que as filiais se tornam mais distantes de suas matrizes, aumentando os custos associados à comunicação, à língua e às diferenças culturais, além dos custos de informação local e o fato de não estarem inseridas nas redes domésticas.

Tanto a existência de uma fronteira comum quanto de língua comum tendem a impactar positivamente os fluxos de IDE. Se países compartilham uma mesma fronteira, espera-se que os fluxos de investimento entre eles sejam mais importantes devido aos menores custos de transação. Compartilhar a mesma língua também reduz os custos de transação, pois facilita o controle do investidor sobre a sua empresa, assim como reflete maior familiaridade entre ambos, por apresentar histórias comuns ou similaridades culturais (Guerin, 2006). Ou seja, estes fatores influenciam os fluxos de IDE devido ao fato de os investidores serem atraídos por países institucionalmente e culturalmente parecidos.

A variável isolamento (ou distância relativa) representa a distância média de um determinado país em relação ao conjunto de seus parceiros, considerando sua importância econômica. No caso dos fluxos de comércio, supõe-se que quanto mais distante o país $i$ estiver de todos os seus parceiros, mantida constante a distância entre os países $i$ e $j$, maiores serão suas importações do país $j$ (Polak,

(7) Para maiores detalhes sobre o modelo gravitacional, ver Head (2003). 
1996 apud Dascal; Mattas; Tzouvelekas, 2002, p. 141). No caso do IDE, o isolamento de um país pode aumentar os fluxos entre as nações, se o IDE for horizontal (sendo comércio e IDE substitutos), e reduzi-los, se o investimento direto for do tipo vertical (neste caso, comércio e investimento são complementares). Egger e Pfaffermayr (2004) chamam a atenção para o fato de que a intensidade dos fluxos bilaterais de investimento está relacionada com a distância entre terceiros países e o país hospedeiro.

Enfim, a mensuração do efeito dos acordos de integração econômica sobre os fluxos de IDE é realizada através da introdução de variáveis dummies, que indicam a participação ou não dos países em dado acordo, conforme feito por Castilho (2001). As variáveis dummies podem ser desmembradas de forma a captar os efeitos de criação e desvio de investimento, conforme veremos adiante.

\subsection{Especificação do modelo}

De acordo com a seção anterior, a especificação da equação gravitacional estimada neste trabalho é:

$$
\begin{aligned}
& \ln \mathrm{IDE}_{\mathrm{ij}}=\alpha \ln \mathrm{y}(\mathrm{ppc})_{\mathrm{it}}+\alpha_{1} \operatorname{lny}(\mathrm{ppc})_{\mathrm{jt}}+\alpha_{2} \ln _{\mathrm{ypcap}_{\mathrm{it}}}+\alpha_{3} \ln _{\mathrm{ypcap}}+\alpha_{\mathrm{jt}} \ln _{4} \mathrm{dist}_{\mathrm{ij}}+\alpha_{5} \text { língua }_{\mathrm{ij}} \\
& +\alpha_{6} \text { fronteira }_{\mathrm{ij}}+\alpha_{7} \text { colonia }_{\mathrm{ij}}+\alpha_{9} \text { isolamento }_{\mathrm{it}}+\alpha_{10} \text { isolamento }_{\mathrm{jt}}+\alpha_{12} \mathrm{ARC}_{\mathrm{ij}}+\mathrm{e}_{\mathrm{ij}}
\end{aligned}
$$

Onde as variáveis são definidas conforme se segue.

- $y(p p c)_{i t}=$ PIB do país de origem, deflacionado pela paridade do poder de compra

- $\mathrm{y}(\mathrm{ppc})_{\mathrm{jt}}=$ PIB do país hospedeiro, deflacionado pela paridade do poder de compra

- ypcap $_{\text {it }}=$ PIB per capita do país de origem, deflacionado pela paridade do poder de compra

- ypcap $_{\mathrm{jt}}=$ PIB per capita do país de destino, deflacionado pela paridade do poder de compra

- dist $_{\mathrm{ij}}=$ distância entre os países i e j

- Dummy "fronteira", que toma o valor 1 se os dois países compartilham uma mesma fronteira e 0 caso contrário.

- Dummy "língua", que toma valor 1 se os países falam o mesmo idioma e 0 caso contrário. 
- Dummy "colônia", que assume valor 1 caso haja alguma relação colonial entre os países e 0 caso contrário, como utilizado por Head e Mayer (2000).

- "Isolamento" ou distância ponderada, obtida por meio do seguinte cálculo: distpond $_{\mathrm{ij}}=\frac{\sum_{j \neq j^{*}}\left(\operatorname{dist}_{\mathrm{ij}}{ }^{*} \mathrm{PIB}_{\mathrm{j}}\right)}{\sum_{j=j^{*}}\left(\mathrm{PIB}_{\mathrm{j}}\right)}$, em que $\mathrm{j}^{*}$ se refere aos parceiros comerciais, com exceção do país que está sendo avaliado.

- ARC refere-se ao conjunto de dummies representativas dos acordos comerciais. Cada acordo avaliado será representado por três dummies:

- D_intrabloco_acordo $=1$ se ambos são membros do mesmo bloco, 0 caso contrário. Sinaliza o efeito de criação de investimento, isto é, o aumento do IDE entre os países membros a partir da constituição do acordo.

- D_hosp_membro = 1 se o país hospedeiro é membro de um acordo e o país de origem não, 0 caso contrário. Reflete a criação de investimento dentro do acordo, por um lado, isto é, o aumento do IDE proveniente de fora do acordo caso o coeficiente seja positivo e, por outro lado, pode estar sinalizando o desvio de investimento para países não membros, uma vez que o IDE pode estar sendo redirecionado para países membros em detrimento dos últimos.

- D_invest_membro = 1 se o país investidor é membro de um acordo e o país receptor não. Isso sinaliza a criação de investimento para fora da região de integração, sendo incentivado talvez pelo aumento de escala proporcionado pela região de integração, ou desvio de investimento caso o coeficiente seja negativo, sinalizando redução de investimento para países extrabloco dada a maior atratividade da região de integração.

\subsection{Base de dados}

A análise dos efeitos da integração sobre os fluxos de IDE é feita para um painel de 71 países. Para isso, foi construída uma base de dados com a maior cobertura geográfica possível, segundo as informações disponíveis para os países. Os dados bilaterais de IDE provêm, sobretudo, das bases da OCDE e da UNCTAD. Porém, como os dados são muito díspares entre países e períodos, tentamos completar (e checar) os dados com informações de outras instituições multilaterais ou até nacionais a fim de cobrir países importantes como Rússia e Hungria. Isto nem sempre foi possível.

Os dados do PIB e de população provêm da base de dados CHELEM e do Centre d'Etudes Prospectives et d'Informations Internacionales (CEPII). Quanto 
às informações referentes às variáveis colônia, idioma comum e distância geográfica, foram também obtidas junto ao CEPII ${ }^{8}$. A partir dos dados de distância e PIB foram calculadas as distâncias ponderadas. Enfim, o site da OMC disponibiliza as informações referentes aos acordos regionais de comércio, possibilitando a criação de dummies relativas à integração.

Nossa amostra tem um total de 71 países, incluindo tanto países desenvolvidos quanto em desenvolvimento, durante o período estudado, ou seja, os anos 1990 a 2003. Porém, nosso painel é desbalanceado, visto que não dispomos de todos os dados para todos os anos e países. A análise é efetuada para 11 acordos regionais ${ }^{9}$ que se referem aos acordos em vigência a partir dos anos 90 , envolvendo os países da nossa amostra. A listagem detalhada dos acordos com os países e respectivas datas de entrada encontra-se em anexo.

\subsection{Considerações metodológicas}

Apesar do sucesso empírico dos modelos gravitacionais, que normalmente explicam parte significativa dos fluxos analisados, diversas questões metodológicas continuam em aberto. Em primeiro lugar, a maioria dos modelos é estimada a partir de uma forma logarítmica que estabelece uma relação linear entre as variáveis e é justificada pela origem multiplicativa do modelo (Head, 2003). Entretanto, o uso da especificação log-log no modelo gravitacional implica na perda de observações ao eliminar os fluxos nulos e negativos ${ }^{10}$ da variável dependente. Tal omissão prejudica os resultados, dependendo do número de fluxos omitidos, uma vez que, nessas observações, há informações importantes no que tange à explicação dos fluxos de baixo valor. Existem diversas propostas para evitar a omissão de fluxos nulos.

Eichengreen e Irwin (1996) propõem que a variável dependente seja definida por: $\ln \left(1+\right.$ fluxo $^{11}$. Levy-Yeyati; Panizza e Stein (2002) propõem uma transformação deste indicador de forma a considerar o sinal negativo no caso de "desinvestimento externo", sendo a variável expressa da seguinte forma: sinal (IDE) $\ln (1+|\mathrm{IDE}|)$.

Outra maneira de tratar os zeros é mediante o método de Heckman para a correção do viés de seleção proveniente da não consideração dos fluxos nulos. $\mathrm{Na}$ primeira etapa, estima-se um modelo Probit no qual são calculadas as

(8) http://www.cepii.fr.

(9) São eles: ASEAN, BAFTA, CAN, CEFTA, CER, CIS, EAEC, EC, EFTA, Mercosul, NAFTA. Para a lista de países e nome dos acordos, ver Anexo 1.

(10) Caso estejamos tratando de fluxos líquidos (Eichengreen; Irwin, 1996).

(11) No caso da variável em questão neste trabalho: $\ln \left(\mathrm{IDE}_{\mathrm{ij}}+1\right)$ 
probabilidades dos fluxos serem positivos, condicionadas às variáveis independentes do modelo. Na segunda etapa, a esperança condicional dos fluxos positivos é introduzida na equação principal por meio da estatística Mills. Estimase, então, a equação principal por mínimos quadrados. Segundo Hilberry (1999), citado por Castilho (2001), a omissão dos fluxos nulos não altera os resultados, caso seu número não seja muito elevado, o que, para o autor, corresponde a um percentual inferior a $10 \%$ dos fluxos totais.

Quanto às técnicas de estimação, há divergências nas opiniões dos autores sobre qual o método mais adequado a utilizar. Tanto os métodos de pooled crosssection (PCS) quanto cross-section geram resultados enviesados (Cheng; Wall, 1999). Para superar este problema é sugerido que seja utilizado o modelo com efeitos fixos, que melhor controla a heterogeneidade. No modelo de efeitos fixos é incluído um intercepto na equação gravitacional, que se refere ao efeito específico aos pares de países e implícitos os efeitos das variáveis bilaterais omitidas, constantes ao longo do tempo. O modelo de efeitos fixos leva em conta elementos não observados, ou melhor, a heterogeneidade não observada.

A situação de heterogeneidade pode surgir devido a elementos étnicos, culturais ou históricos, políticos e geográficos que não são captados pelas diversas variáveis do modelo e que influenciam o nível da variável dependente em questão, correlacionando-se com as demais variáveis independentes. Diversos destes fatores revelam-se de difícil representação e quantificação. Neste caso, variáveis constantes no tempo, como distância e fronteira, deixam de ser estimadas separadamente e seus efeitos passam a ser captados pelos coeficientes dos termos constantes bilaterais. Isso impede problemas de má adequação do modelo, oriundos da omissão de variáveis fixas no tempo, relevantes para estimação do modelo.

Anderson e van Wincoop (2003), por sua vez, apontam problemas de especificação em um modelo gravitacional padrão, visto que não inclui uma variável que represente a "resistência multilateral". Os autores propõem a inclusão de efeitos fixos individuais na equação, isto é, efeitos fixos por país, ao invés de efeitos fixos para pares de países, sugerido por Cheng e Wall (1999). Ou seja, a variável omissa mais relevante a ser captada pelos efeitos fixos seria o nível de proteção médio de cada país, no caso dos primeiros, e não características inerentes aos pares de países, no caso dos últimos. Em relação ao IDE, a proteção deve ser menos relevante que para os fluxos comerciais, porém, outras características institucionais, por exemplo, específicas a cada país, poderão estar melhor representadas por efeitos fixos por país. 
Conforme Silva e Tenreyro (2005), a existência de fluxos nulos faz com que os fluxos não tenham distribuição normal e propõem, então, o método de "Poisson Pseudo-Maximum Likelyhood" (PPML). Logo, ao invés de utilizar os métodos de mínimos quadrados lineares, os autores recomendam a utilização deste método, que permite a consideração da informação contida nos fluxos nulos sem recorrer a transformações $a d$ hoc da variável a ser explicada.

Segundo os autores, há evidências de que os erros dos modelos gravitacionais $\log$ lineares são heterocedásticos e, portanto, dependentes dos regressores $^{12}$, gerando, então, resultados inconsistentes. Com respeito aos vários tratamentos dos zeros da variável dependente geralmente utilizados (como o uso do estimador tobit, da mudança da variável dependente para $\left(1+\mathrm{F}_{\mathrm{ij}}\right)$ ou do

cancelamento dos fluxos nulos), verifica-se que resultam em estimadores inconsistentes. Essa inconsistência pode ser proveniente de erros de medida, pois os zeros são muitas vezes oriundos de erros de arredondamento ou da ausência de observações. A alternativa proposta por Silva e Tenreyro (2005) é, então, o método de Poisson, que fornece estimativas robustas na presença de heterocedasticidade ${ }^{13}$, além de tratar os zeros da variável dependente de uma forma natural $^{14}$.

\subsection{Estratégia de estimação}

Devido à divergência exposta acima, no que se refere às técnicas de estimação mais apropriadas para a estimação do modelo gravitacional, empregamos aqui diversas técnicas econométricas. Assim, tentamos, por um lado, testar a robustez dos resultados obtidos a partir dos diversos métodos e, por outro, averiguar se os métodos se mostram adaptados ao tema analisado.

Ao efetuarmos o teste de Breüsch e Pagan para detectar alguma forma linear de heterocedasticidade, conforme assinalado em Vallejo e Aguilar (2004), detectou-se a ocorrência de efeitos de painel, ou melhor, a presença de variâncias iguais dos erros. Por isso, não empregamos o método de mínimos quadrados neste artigo.

(12) Segundo Silva e Tenreyro (2005), neste caso, E(ln y) $\neq \ln E(y)$, desigualdade (de Jensen) que é ignorada por diversos trabalhos empíricos e que leva a estimativas enviesadas e interpretações inadequadas dos coeficientes estimados por métodos tradicionais. Este seria o caso das estimações por mínimos quadrados ou com controle de efeitos fixos individuais, conforme Anderson e van Wincoop (2003).

(13) O método pondera as observações e toda a estimação é baseada na matriz de estimadores de covariância robusta Eicker-White.

(14) Silva e Tenreyro (2005) sustentam que o PPML é superior não só aos métodos enumerados acima, mas também ao método dos Mínimos Quadrados Não Lineares, cujos estimadores podem se mostrar ineficientes, uma vez que este método negligencia o problema de heterocedasticidade. Ao ponderar as observações, este método fornece muitas vezes peso maior a observações com maior variância, gerando a ineficiência do estimador. 
Com relação aos modelos em painel, com a finalidade de detectar qual o melhor modelo a ser usado na estimação da equação, o efeito fixo ou o aleatório, utilizamos o teste de Hausman. Este teste nos permite avaliar qual seria o modelo mais adequado sob a hipótese nula de que os efeitos específicos são não correlacionados com as demais variáveis independentes, característica em que é apropriado o uso de efeitos aleatórios ${ }^{15}$. Uma vez rejeitada a hipótese nula, a melhor alternativa seria utilizar o modelo de efeitos fixos. Este método parece mais adequado também pelas características de nossa amostra - um conjunto relativamente constante de pares de países. No entanto, encontramos alguns problemas, como a anulação de alguns blocos comerciais, como veremos adiante.

Os métodos aqui empregados foram:

i) MQO com dados empilhados (pooled cross-section - PCS), a fim de controlar padrões cíclicos da amostra através da captura do efeito tempo por meio da dummy tempo (Guerin, 2006). O método exige a restrição de que o vetor de parâmetros seja igual para todos os anos, variando somente o intercepto ao longo do tempo (Cheng; Wall, 1999).

ii) modelo de efeitos fixos por país para controle das especificidades de cada país, constantes no tempo, e efeitos fixos por ano (efeito tempo);

iii) modelo de painel por par de países que controla as especificidades de cada par de países constantes no tempo;

iv) o método de Poisson.

Além disso, empregamos a técnica de correção dos zeros, sugerida por Eichengreen e Irwin (1996), nos modelos de efeitos fixos e de dados empilhados.

\subsection{Resultados}

A Tabela 2, exibida adiante, mostra os resultados dos métodos descritos acima, isto é, os métodos de Poisson, dados empilhados (PCS), de efeitos fixos por país e por ano e, enfim, efeitos fixos por par de países, sendo que os três últimos utilizam o método de correção dos fluxos nulos proposto por Eichengreen e Irwin (1996).

Conforme podemos notar, a variável distância mostrou-se estatisticamente significativa e com o sinal negativo esperado em todas as especificações, indicando o impacto negativo da distância sobre o IDE. A variável PIB do país

(15) Os efeitos aleatórios assim como os efeitos fixos controlam as variáveis omitidas constantes ao longo do tempo que variam entre os casos, embora os primeiros controlem também as variáveis constantes entre os casos e que variam ao longo do tempo. Nesse sentido, as diferenças individuais no intercepto de cada unidade do corte transversal refletem-se no termo de erro ao invés das diferenças no intercepto. O uso dos efeitos aleatórios é mais adequado quando os erros e as variáveis independentes não estão correlacionados, caso contrário, o modelo de efeito fixo pode ser o mais apropriado. 
investidor é estatisticamente significativa em todos os casos, porém os coeficientes são negativos nos métodos de efeitos fixos, diferentemente dos demais. Já na variável PIB do país hospedeiro, além de ser estatisticamente significativa em todos os métodos, os coeficientes são positivos, em sua maioria, conforme o esperado, salvo no modelo de efeito fixo por país. A existência de coeficientes negativos da variável PIB nos modelos apontados pode estar relacionada à introdução dos efeitos fixos que já captam, em grande parte, os efeitos de tamanho e nível de desenvolvimento dos países ${ }^{16}$.

No tocante à variável PIB per capita do país investidor, esta revela-se estatisticamente significativa em todas as estimações e apresenta coeficientes significativos e com o sinal positivo esperado, o que indica que o nível de desenvolvimento do país investidor é um importante determinante do investimento direto. Da mesma forma, a variável PIB per capita do país hospedeiro também se mostra um importante atrativo para o IDE, uma vez que a variável é estatisticamente significativa e apresenta coeficiente com sinal positivo na maioria das estimações. Apenas no método de efeito fixo por par de países, a variável se mostra estatisticamente não significativa, o que pode ser explicado também pela incorporação dos efeitos fixos, conforme esclarecido anteriormente.

Tabela 2

Resultados das estimações

\begin{tabular}{lcccc}
\hline & Poisson & PCS & $\begin{array}{c}\text { Efeito fixo } \\
\text { país/ano }\end{array}$ & $\begin{array}{c}\text { Efeito fixo par } \\
\text { de países }\end{array}$ \\
\hline Variável dependente & Ide & lide_c(1) & lide_c(1) & lide_c(1) \\
\hline Variáveis gravitacionais: & & & & \\
\hline Distância & -0.800 & -0.469 & -0.441 & -1.183 \\
Ldist & $(0.000)^{* *}$ & $(0.000)^{* *}$ & $(0.000)^{* *}$ & $()$. \\
\hline PIB PPA investidor & 0.718 & 0.518 & -1.957 & -0.862 \\
lpibppa_inv & $(0.000)^{* *}$ & $(0.000)^{* *}$ & $(0.000)^{* *}$ & $(0.000)^{* *}$ \\
\hline PIB PPA hospedeiro & 0.469 & 0.399 & -1.054 & 1.309 \\
lpibppa_hosp & $(0.000)^{* *}$ & $(0.000)^{* *}$ & $(0.011)^{*}$ & $(0.000)^{* *}$ \\
\hline PIB per capita investidor & 2.332 & 0.958 & 2.479 & 1.807 \\
lpibppa_pcap_inv & $(0.000)^{* *}$ & $(0.000)^{* *}$ & $(0.000)^{* *}$ & $(0.000)^{* *}$ \\
\hline PIB per capita hospedeiro & 1.009 & 0.336 & 1.011 & -0.245 \\
lpibppa_pcap_hosp & $(0.000)^{* *}$ & $(0.000)^{* *}$ & $(0.013)^{*}$ & $(0.438)$ \\
\hline Dist. ponderada investidor & -0.984 & -0.449 & 0.760 & -1.363 \\
ldistpond_inv & $(0.000)^{* *}$ & $(0.000)^{* *}$ & $(0.000)^{* *}$ & $(0.006)^{* *}$ \\
\hline Dist. ponderada hospedeiro & 0.883 & 0.169 & 0.776 & 5.143 \\
ldistpond_hosp & $(0.001)^{* *}$ & $(0.050)^{*}$ & $(0.030)^{*}$ & $(0.000)^{* *}$ \\
\hline
\end{tabular}

Continua...

(16) Segundo Vallejo e Aguilar (2004, p. 18): “(...) los efectos fijos por país y los efectos de tiempo pueden estar capturando por lo menos parte del tamaño de mercado y nivel de desarrollo de las diferentes naciones, y por lo tanto, una vez esos efectos panel se incluyen, los coeficientes del PIB y del PIB per capita se vuelven poco confiables." 
Tabela 2 - Continuação

\begin{tabular}{|c|c|c|c|c|}
\hline & Poisson & PCS & $\begin{array}{l}\text { Efeito fixo } \\
\text { país/ano }\end{array}$ & $\begin{array}{c}\text { Efeito fixo par } \\
\text { de países }\end{array}$ \\
\hline Variável dependente & Ide & lide_c(1) & lide_c(1) & lide_c(1) \\
\hline Fronteira comum & -0.590 & 0.433 & 0.475 & 0.000 \\
\hline Contiguity & $(0.002)^{* *}$ & $(0.000)^{* *}$ & $(0.000)^{* *}$ & (.) \\
\hline Língua comum & 0.587 & 1.037 & 0.814 & 0.000 \\
\hline comlang_off & $(0.000)^{* *}$ & $(0.000)^{* *}$ & $(0.000)^{* *}$ & $()$. \\
\hline Relação colonial & 0.449 & 0.742 & 0.834 & 0.000 \\
\hline Colony & $(0.000)^{* *}$ & $(0.000)^{* *}$ & $(0.000)^{* *}$ & $()$. \\
\hline \multicolumn{5}{|l|}{ Variáveis integração: } \\
\hline Mercosul intrabloco & 1.694 & 1.185 & 1.148 & 2.916 \\
\hline$d M S \_$int & $(0.000)^{* *}$ & $(0.001)^{* *}$ & $(0.007)^{* *}$ & $(0.000)^{* *}$ \\
\hline Mercosul hosp_membro & 1.642 & 0.798 & 0.423 & 0.250 \\
\hline$d M S \_i n v \_e x t$ & $(0.000)^{* *}$ & $(0.000)^{* *}$ & $(0.027)^{*}$ & $(0.221)$ \\
\hline Mercosul invest_membro & 0.258 & -0.257 & -0.086 & -0.307 \\
\hline dMS_hosp_ext & $(0.390)$ & $(0.000)^{* *}$ & $(0.508)$ & $(0.004)^{* *}$ \\
\hline ASEAN intrabloco & 3.630 & 2.380 & -3.380 & 0.000 \\
\hline dASEAN_int & $(0.000)^{* *}$ & $(0.000)^{* *}$ & $(0.000)^{* *}$ & $()$. \\
\hline ASEAN hosp_membro & 1.272 & 0.974 & 0.000 & 0.000 \\
\hline dASEAN_inv_ext & $(0.001)^{* *}$ & $(0.000)^{* *}$ & $()$. & $()$. \\
\hline ASEAN invest_membro & 1.443 & 0.497 & -4.634 & 0.000 \\
\hline dASEAN_hosp_ext & $(0.000)^{* *}$ & $(0.000)^{* *}$ & $(0.000)^{* *}$ & $()$. \\
\hline BAFTA intrabloco & 2.279 & 0.973 & 0.000 & 0.000 \\
\hline dBAFTA_int & $(0.000)^{* *}$ & $(0.001)^{* *}$ & $()$. & $()$. \\
\hline BAFTA hosp_membro & -0.179 & 0.685 & 0.004 & 0.000 \\
\hline dBAFTA_inv_ext & $(0.553)$ & $(0.000)^{* *}$ & $(0.991)$ & (.) \\
\hline BAFTA invest_membro & -1.578 & -0.006 & -0.472 & -0.351 \\
\hline dBAFTA_hosp_ext & $(0.001)^{* *}$ & $(0.894)$ & $(0.000)^{* *}$ & $(0.000)^{* *}$ \\
\hline CAN intrabloco & 2.649 & 0.379 & 0.000 & 0.000 \\
\hline$d C A N \_$int & $(0.000)^{* *}$ & $(0.010)^{*}$ & $()$. & $()$. \\
\hline CAN hosp_membro & 0.453 & 0.364 & 4.243 & 0.000 \\
\hline dCAN_inv_ext & $(0.045)^{*}$ & $(0.000)^{* *}$ & $(0.004)^{* *}$ & $()$. \\
\hline CAN invest_membro & 0.051 & 0.169 & -4.240 & 0.000 \\
\hline$d C A N \_h o s p \_e x t$ & $(0.910)$ & $(0.000)^{* *}$ & $(0.004)^{* *}$ & $()$. \\
\hline CEFTA intrabloco & -0.558 & -0.754 & -0.143 & -0.051 \\
\hline dCEFTA_int & $(0.248)$ & $(0.000)^{* *}$ & $(0.173)$ & $(0.569)$ \\
\hline CEFTA hosp_membro & 0.101 & 0.255 & 0.405 & 0.536 \\
\hline dCEFTA_inv_ext & $(0.547)$ & $(0.000)^{* *}$ & $(0.000)^{* *}$ & $(0.000)^{* *}$ \\
\hline CEFTA invest_membro & -0.587 & -0.954 & -0.465 & -0.299 \\
\hline dCEFTA_hosp_ext & $(0.328)$ & $(0.000)^{* *}$ & $(0.000)^{* *}$ & $(0.000)^{* *}$ \\
\hline CER intrabloco & 2.262 & 3.950 & -3.877 & 0.000 \\
\hline dCER_int & $(0.000)^{* *}$ & $(0.000)^{* *}$ & $(0.064)$ & $()$. \\
\hline CER hosp_membro & 0.321 & 0.583 & 6.222 & 0.000 \\
\hline$d C E R \_i n v \_$ext & $(0.199)$ & $(0.000)^{* *}$ & $(0.000)^{* *}$ & $()$. \\
\hline CER invest_membro & 0.638 & 0.140 & -13.457 & 0.000 \\
\hline dCER_hosp_ext & $(0.015)^{*}$ & $(0.045)^{*}$ & $(0.000)^{* *}$ & $()$. \\
\hline CIS intrabloco & -1.996 & 0.462 & 0.000 & 0.000 \\
\hline$d C I S \_i n t$ & $(0.006)^{* *}$ & $(0.092)$ & $()$. & $()$. \\
\hline
\end{tabular}


Impacto da integração regional sobre os fluxos mundiais de Investimento Direto

Tabela 2 - Continuação

\begin{tabular}{|c|c|c|c|c|}
\hline & Poisson & PCS & $\begin{array}{l}\text { Efeito fixo } \\
\text { país/ano }\end{array}$ & $\begin{array}{c}\text { Efeito fixo par } \\
\text { de países }\end{array}$ \\
\hline Variável dependente & Ide & lide_c(1) & lide_c(1) & lide_c(1) \\
\hline CIS hosp_membro & 1.201 & 0.778 & -0.360 & 0.000 \\
\hline$d C I S \_i n v \_e x t$ & $(0.001)^{* *}$ & $(0.000)^{* *}$ & $(0.177)$ & (.) \\
\hline CIS invest_membro & -1.186 & -0.767 & 0.047 & 0.206 \\
\hline dCIS_hosp_ext & $(0.040)^{*}$ & $(0.000)^{* *}$ & $(0.709)$ & $(0.023)^{*}$ \\
\hline EC intrabloco & 0.766 & 1.381 & 1.210 & 0.034 \\
\hline$d E C_{-}$int & $(0.000)^{* *}$ & $(0.000)^{* *}$ & $(0.000)^{* *}$ & $(0.759)$ \\
\hline EC hosp_membro & 0.529 & 0.205 & 0.036 & -0.265 \\
\hline dEC_inv_ext & $(0.000)^{* *}$ & $(0.000)^{* *}$ & $(0.399)$ & $(0.000)^{* *}$ \\
\hline EC invest_membro & 0.098 & 0.334 & 0.090 & -0.143 \\
\hline dEC_hosp_ext & $(0.575)$ & $(0.000)^{* *}$ & $(0.242)$ & $(0.273)$ \\
\hline EFTA intrabloco & 0.217 & 0.493 & 0.593 & -0.467 \\
\hline dEFTA_int & $(0.300)$ & $(0.002)^{* *}$ & $(0.000)^{* *}$ & $(0.010)^{* *}$ \\
\hline EFTA hosp_membro & 0.193 & 0.175 & 0.084 & -0.209 \\
\hline dEFTA_inv_ext & $(0.449)$ & $(0.000)^{* *}$ & $(0.167)$ & $(0.001)^{* *}$ \\
\hline EFTA invest_membro & -0.053 & 0.298 & 0.374 & -0.208 \\
\hline dEFTA_hosp_ext & $(0.829)$ & $(0.000)^{* *}$ & $(0.000)^{* *}$ & $(0.060)$ \\
\hline NAFTA intrabloco & 0.380 & 3.047 & 1.763 & 1.117 \\
\hline$d N A F T A \_i n t$ & $(0.104)$ & $(0.000)^{* *}$ & $(0.000)^{* *}$ & $(0.000)^{* *}$ \\
\hline NAFTA hosp_membro & 1.266 & 0.849 & 0.162 & 0.188 \\
\hline dNAFTA_inv_ext & $(0.000)^{* *}$ & $(0.000)^{* *}$ & $(0.081)$ & $(0.002)^{* *}$ \\
\hline NAFTA invest_membro & 0.252 & 0.611 & 0.371 & 0.504 \\
\hline dNAFTA_hosp_ext & $(0.039)^{*}$ & $(0.000)^{* *}$ & $(0.001)^{* *}$ & $(0.000)^{* *}$ \\
\hline EAEC intrabloco & 4.987 & -0.260 & -0.328 & 0.751 \\
\hline dEAEC_int & $(0.000)^{* *}$ & $(0.478)$ & $(0.330)$ & $(0.047)^{*}$ \\
\hline EAEC hosp_membro & -0.299 & 0.108 & -0.024 & 0.261 \\
\hline$d E A E C \_i n v \_$ext & $(0.359)$ & $(0.369)$ & $(0.848)$ & $(0.002)^{* *}$ \\
\hline EAEC invest_membro & -0.489 & -0.186 & -0.430 & -0.336 \\
\hline dEAEC_hosp_ext & $(0.337)$ & $(0.005)^{* *}$ & $(0.000)^{* *}$ & $(0.000)^{* *}$ \\
\hline Constante & -36.421 & -15.976 & -0.239 & -41.931 \\
\hline Constant & $(0.000)^{* *}$ & $(0.000)^{* *}$ & $(0.959)$ & (.) \\
\hline Observações & 23413 & 23932 & 23932 & 23932 \\
\hline $\mathrm{R}^{2}$ & n.d. & 0.556 & 0.669 & 0.822 \\
\hline
\end{tabular}

Notas: (1) lide_c $=$ Ln IDE corrigido segundo Eichengreen e Irwin (1996); p-valor entre parênteses; *,**: significativos a 1 e $5 \%$ respectivamente. Valores de p robustos (método de White). Elaboração própria.

Com respeito à distância ponderada do país investidor, revela-se, na maioria das estimações, que, quanto maior a distância do país investidor em relação ao conjunto dos demais países, menor a realização de investimento direto estrangeiro $^{17}$. O menor investimento pode ser explicado pela complementaridade existente entre IDE e comércio, sinalizando a presença do IDE de tipo vertical.

(17) A única exceção é no modelo de efeito fixo por país, onde a variável se mostra estatisticamente não significativa. 
Neste caso, a redução do investimento se dá em função da retração do comércio diante do maior custo de transporte. A outra razão seria o maior custo envolvido entre a filial e a matriz, dificultando o contato entre elas. Já a distância ponderada do país hospedeiro exerce um impacto positivo sobre o IDE em todas as estimações, diferentemente do esperado. Isso sugere a presença de IDE horizontal, uma vez que o maior investimento para o país isolado pode representar o interesse por esse mercado, sendo, nesse caso, IDE e comércio substitutos.

As variáveis língua comum e relação colonial mostraram-se estatisticamente significativas, com coeficientes positivos, sendo, portanto, fatores que contribuem para o aumento dos fluxos de IDE. Ou seja, países que apresentam a mesma língua ou que apresentam laços coloniais tendem a realizar IDE entre eles. No entanto, a variável fronteira apresenta coeficiente negativo no método de Poisson, contrariamente aos demais métodos cujos resultados apresentaram sinais positivos, conforme o esperado.

Os coeficientes referentes aos efeitos da integração variam bastante entre as especificações e entre os blocos. No que se refere às dummies de IDE intrabloco, alguns se mostraram estatisticamente significativos, com coeficientes positivos, conforme o esperado, em todas as estimações, tais como as dummies dos blocos Mercosul, BAFTA e CAN, ressaltando que há casos em que a variável foi suprimida nos modelos de efeitos fixos. Tais resultados podem insinuar a predominância de IDE vertical nas regiões, uma vez que, nesse caso, IDE e comércio são complementares. Dessa forma, o IDE pode se especializar verticalmente de modo a explorar vantagens comparativas dos outros países, aumentando o comércio intrafirma, assim como pode haver apenas o deslocamento de unidades produtivas. Há outros blocos em que a variável se revela estatisticamente significativa e com o sinal esperado na maioria das estimações, embora não em todas. São eles: ASEAN, CER, EC, NAFTA. As dummies referentes aos blocos CER e ASEAN apresentaram coeficientes negativos no modelo de efeito fixo por país. O coeficiente negativo pode estar simbolizando o aumento do comércio intrarregional em detrimento do IDE, sinalizando IDE e comércio como substitutos. As variáveis intrarregionais dos blocos UE e NAFTA mostram-se estatisticamente não significativas apenas nos modelos de efeito fixo por par de países e de Poisson, respectivamente. A variável intrarregional do acordo CEFTA mostrou-se estatisticamente não significativa em praticamente todos os métodos, com exceção do método pooled cross-section, cujo coeficiente apresentou sinal negativo e a variável se revelou estatisticamente significativa.

Nos demais acordos, os impactos da integração são diversos, dificultando a realização de inferências. No acordo CIS, por exemplo, a variável apresenta coeficiente negativo no método de Poisson e coeficiente positivo no PCS, sendo 
estatisticamente significativa a $10 \%$ de significância no último caso. Além disso, não é permitido realizar inferência nos demais métodos visto que a variável foi cancelada. No que se refere ao acordo EFTA, os resultados também não foram robustos. A dummy intrarregional do bloco EFTA revelou-se estatisticamente não significativa no método de Poisson, ao contrário das demais estimações em que as variáveis são estatisticamente significativas. Porém, nos métodos, pooled crosssection e de efeito fixo por país, o coeficiente apresenta o resultado esperado, isto é, coeficiente positivo, enquanto no modelo de efeito fixo por par de países o coeficiente é negativo. No bloco EAEC, a variável é estatisticamente não significativa nos métodos de pooled cross-section e de efeito fixo por país e nos demais apresenta o resultado esperado.

A dummy que avalia a relação entre um país membro hospedeiro de um acordo regional e países que não integram o bloco registra resultados esperados na maioria das estimações, ou seja, resultados estatisticamente significativos e coeficientes positivos. Este é o caso do Mercosul, embora a variável seja estatisticamente não significativa no modelo de efeito fixo por par de países; NAFTA, apesar de a variável ser significativa, considerando apenas 10\% de significância no modelo de efeito fixo por país; ASEAN, CAN e CEFTA, embora a variável tenha sido estatisticamente não significativa no método de Poisson; de modo similar, o CER e, enfim, o CIS, apesar de a variável ser estatisticamente não significativa no método de efeito fixo por país.

O aumento do IDE pode, por um lado, ter como motivação o aumento do mercado gerado pela formação do acordo e a firma estabelecer-se em um país membro, utilizando-o como plataforma de exportação para os demais países membros. Este IDE pode se enquadrar no tipo de IDE de bens diferenciados, cuja produção final é destinada para o mercado local e externo. Por outro, o IDE pode ser do tipo tariff-jumping, sendo motivado pela incidência de tarifas nas transações de mercadorias entre membros e não membros. Nesse sentido, IDE e comércio são substitutos, sendo predominante o IDE do tipo horizontal. Contrariamente, o EAEC constitui-se como o único bloco no qual, na maioria das estimações, a variável se mostrou estatisticamente não significativa, exceto no método de efeito fixo por par de países, onde os coeficientes apresentaram um aumento dos fluxos de IDE provenientes de países não membros. Quanto ao bloco EFTA, os resultados foram díspares, sinalizando aumento do IDE na estimação pelo método pooled cross-section e redução no método de efeito fixo por par de países, enquanto nos demais métodos a variável mostrou-se estatisticamente não significativa. A dummy que representa o bloco EC revelou-se estatisticamente não significativa no método de efeito fixo por país, enquanto, nos métodos de PCS e Poisson, a variável mostrou-se estatisticamente significativa, com coeficiente positivo. Já no método proposto por Cheng e Wall (1999), o coeficiente apresenta 
sinal negativo, sinalizando redução do investimento direto na região devido ao aumento da concorrência gerada com a constituição do bloco. Em relação ao BAFTA, os resultados também não se mostraram robustos, sendo a variável estatisticamente não significativa no modelo sugerido por Anderson e Wincoop (2003) e Poisson, apresentando o sinal positivo esperado e variável estatisticamente significativa no método pooled cross-section.

Ao avaliar a relação existente entre um país membro investidor e os países que não compõem o bloco, os resultados para maioria dos acordos foram bastante díspares, sendo o bloco NAFTA a única exceção na qual a variável se mostrou estatisticamente significativa e apresentou coeficiente positivo em todas as estimações. Uma motivação possível para essa realização de IDE é o aumento de escala proveniente da formação do acordo comercial. Os blocos EAEC, CIS, CEFTA e BAFTA também merecem destaque, pois em praticamente todas as estimações a variável revelou-se estatisticamente significativa e com coeficiente negativo. Isso pode estar refletindo desvio de investimento, dado o menor incentivo ao investimento fora da região de integração devido à permanência de tarifas entre membros e não membros, talvez pelo fato de o IDE ser do tipo vertical e complementar ao comércio. Nesse sentido, o IDE é direcionado para os países membros em detrimento dos países não membros, dada a ausência de tarifas a partir da formação do bloco.

Os resultados revelaram-se muito diferenciados segundo a técnica utilizada nos demais acordos. A variável que representa o Mercosul mostrou-se estatisticamente não significativa nos modelos de efeito fixo por país e Poisson, sendo estatisticamente significativa e com sinal negativo nos métodos restantes. Os sinais foram contraditórios na variável que representa o ASEAN, sendo positivo no PCS e Poisson e negativo no modelo de efeito fixo por país. No acordo CAN, a variável revelou-se estatisticamente significativa e com sinal positivo apenas no modelo pooled cross-section, enquanto no método de efeito fixo por país o coeficiente é negativo e no de Poisson a variável foi estatisticamente não significativa. Com respeito ao CER, a variável mostrou-se estatisticamente significativa nos métodos pooled cross-section e Poisson, com coeficientes positivos. Já quanto ao método de efeito fixo por país, a variável correspondente revelou-se estatisticamente significativa a $10 \%$ de significância e com coeficiente negativo. A dummy referente ao CIS somente se mostrou estatisticamente significativa, com coeficiente positivo, no método de efeito fixo por par de países. Nos métodos de Poisson e pooled cross-section, o coeficiente é negativo, sendo a variável estatisticamente não significativa no método proposto por Anderson e Wincoop (2003). A dummy que diz respeito ao acordo EC mostrou-se estatisticamente não significativa em praticamente todas as estimações, salvo no método PCS, cujo coeficiente é positivo. 


\section{Conclusões}

O crescimento recente e paralelo dos fluxos de IDE e da regionalização da economia mundial sugere que estes dois fenômenos fazem parte de um mesmo processo, que se complementam e se retroalimentam. A literatura teórica aponta para as diversas formas nas quais esta relação pode se estabelecer e mostra que os resultados podem ser ambíguos e desiguais entre países, dependendo do tipo de IDE e da inserção da empresa no mercado.

Neste trabalho, buscou-se avaliar em que medida a integração comercial impactou os fluxos de investimento direto estrangeiro (IDE) durante o período de 1990 a 2003 para um conjunto diverso de países. Em princípio, espera-se um efeito positivo da integração sobre os fluxos de IDE em geral, porém, um exame detalhado dos fluxos bilaterais pode revelar evoluções conflitantes. Em primeiro lugar, pode-se ter criação de investimento - crescimento do IDE intrarregional resultante do aumento dos investimentos entre os países membros devido à liberalização comercial (neste caso, os IDEs seriam complementares ao comércio). Em segundo lugar, relativamente aos parceiros externos, o acordo regional pode, por um lado, tornar a região mais atrativa para investidores extrarregionais, acarretando possivelmente na criação de IDE no bloco e desvio de investimento nos países extrabloco e, por outro, dar condições às empresas locais de concorrerem em terceiros mercados, ampliando, assim, o investimento de países do bloco em países extrabloco, sinalizando a criação de investimento nos mesmos. Neste caso, o aumento de escala proporcionado pelo acordo regional direciona o IDE para países não membros.

Para a avaliação empírica, montou-se uma base de dados com informações sobre os fluxos bilaterais de investimento direto estrangeiro para um amplo e variado conjunto de países a partir do trabalho de coleta e tratamento dos dados provenientes de diferentes bases de dados internacionais. Os dados reunidos formam um painel desbalanceado, com dados para um período de 14 anos, a partir de 1990. Os efeitos de desvio e criação de investimento são estimados a partir do modelo gravitacional, ferramenta amplamente utilizada para a avaliação dos determinantes de fluxos econômicos bilaterais devido à sua boa capacidade explicativa. Este método é, em particular, bastante utilizado para a avaliação dos impactos de integração comercial.

No presente trabalho, utilizamos diferentes métodos de estimação propostos pela literatura recente acerca dos modelos gravitacionais, com um objetivo secundário de comparar os respectivos resultados. Os procedimentos aplicados foram os seguintes: a técnica de Poisson, sugerida para corrigir o problema de heterocedasticidade e que permite a consideração dos fluxos nulos; MQO com dados empilhados (PCS), de modo a controlar os padrões cíclicos da 
amostra; modelo de efeitos fixos por país e por ano, a fim de controlar as características de cada país constantes no tempo e, enfim, o modelo de efeitos fixos por par de países, com o intuito de evitar estimativas enviesadas provenientes de erros de omissão de variáveis referentes às características dos pares de países. Os fluxos nulos foram corrigidos conforme Eichengreen e Irwin (1996) nas últimas 3 estimações.

Os resultados referentes à maioria das variáveis gravitacionais indicam que esta ferramenta tem uma boa capacidade explicativa dos fluxos bilaterais de IDE. Os determinantes geográficos (tais como distância e fronteira comum), econômicos (sobretudo tamanho) e históricos e culturais (língua comum e relação colonial), em geral, explicam bem os fluxos de IDE.

No tocante aos efeitos da integração, os resultados mostraram-se bastante díspares, conforme a técnica e o método utilizados, permitindo confirmar apenas parte dos resultados esperados. A heterogeneidade destes resultados revela, entre outros, que o impacto dos acordos regionais sobre os fluxos de IDE pode ser, por vezes, ambíguo e até mesmo contraditório.

Os resultados foram estimados em separado para investimento intrarregional e extrarregional, sendo este último com o país hospedeiro membro do bloco ou extrarregional com o país investidor membro.

Em primeiro lugar, o processo de integração parece exercer um efeito positivo sobre os fluxos de investimento intrarregionais. Embora este efeito não seja observado para todos os acordos, o crescimento do investimento entre parceiros é observado para o BAFTA, UE, NAFTA, CAN, ASEAN, CER e o Mercosul. Para os demais os resultados são mais sensíveis à especificação. A especialização produtiva vertical nos países, resultante do incentivo à ampliação do comércio intrafirma, assim como a mudança de localização de unidades produtivas para exploração das vantagens comparativas são razões pelas quais a integração estimula o IDE intrarregional.

Em segundo lugar, a integração regional parece aumentar a atratividade dos países membros, possivelmente devido à ampliação do tamanho do mercado consumidor e dos ganhos de eficiência e escala. Os resultados acusam uma relação positiva entre integração e atratividade no caso dos blocos NAFTA, ASEAN, CEFTA, CIS, CER, CAN e Mercosul. Os resultados relativamente fracos observados para a UE devem-se ao período coberto pela presente análise, que não capta o boom de investimento direto na Europa nos anos que precederam à formação do Mercado Único em 1992.

Enfim, no que se refere ao efeito de crescimento dos investimentos dos países membros em terceiros países, os resultados são os menos homogêneos entre 
os diferentes blocos. O único bloco para o qual este efeito é significativo em todas as especificações é o NAFTA. Para os países que o compõem a complementaridade e os ganhos de escala decorrentes da integração reforçaram a capacidade das firmas dos países de atuar internacionalmente. Contrariamente ao NAFTA, as dummies que representam os blocos EAEC, CIS, CEFTA e BAFTA apresentam coeficientes negativos na maioria das estimações, sinalizando a redução do IDE dos países que os compõem para países extrabloco a partir da formação dos acordos.

Ou seja, nossos resultados sugerem que existe uma relação entre integração e IDE, mas que seu sentido pode ter diversas direções. Quanto aos resultados das distintas estimações obtidas, algumas variáveis mostram-se bastante robustas em todas as estimações. É o caso, notadamente, da maior parte das variáveis gravitacionais e dos coeficientes referentes à recepção de fluxos de investimento de terceiros países para a quase totalidade dos acordos. Porém, a heterogeneidade dos resultados obtidos para grande parte das variáveis de integração sugere que determinadas questões metodológicas continuam em aberto, tanto no que se refere ao tratamento dos fluxos nulos e negativos quanto no que se refere à especificação dos modelos em painel. Dessa forma, bases de dados com dimensão tempo abrem portas para novas técnicas ainda pouco exploradas.

Vale salientar que os efeitos dos acordos comerciais podem diferir também segundo os países membros de um mesmo acordo devido às diferenças de políticas inerentes a cada país. Neste sentido, seria interessante aprofundar a análise empírica aqui realizada a fim de ressaltar estas diferenças (entre os países de um mesmo acordo) e tentar entender quais são as razões para tal, visto que fatores como tamanho e riqueza já estão sendo controlados para o conjunto de países.

\section{Referências bibliográficas}

ANDERSON, J. E; van WINCOOP, E. Gravity with gravitas: A solution to the Border Puzzle. American Economic Review, v. 93, n. 1, p. 170-192, 2003.

BID. Beyond borders: the new regionalism in Latin America. Economic and Social Progress in Latin America Report, Washington, BID, 2002.

BLONIGEN, B. A. Foreign Direct Investment behavior of multinational corporations. NBER. National Bureau of Economic Research, 2006.

BLOMSTRÖM, M.; KOKKO, A. Regional integration and Foreign Direct Investment: a conceptual framework and three cases. Washington, DC: World Bank, 1997. (Policy Research Working Paper, n. 1750) 
BOS, J. W. B.; LAAR, M. Explaining Foreign Direct Investment in Central and Eastern Europe: an extended gravity approach. Maastricht: METEOR, Maastricht Research School of Economics of Technology and Organization, 2004.

BRAINARD, L. An empirical assessment of the proximity-concentration trade-off between multinational sales and trade. American Economic Review, 1997.

BRENTON P.; DI MAURO, F.; LÜCKE, M. Economic integration and FDI: an empirical analysis of foreign investment in the EU and in Central and Eastern Europe. Empirica, v. 26 , p. $95-121,1999$.

CALDERÓN, C.; LOAYZA, N.; SERVÉN, L. Greenfield Foreign Direct Investment and mergers and acquisitions: feedback and macroeconomic effects. 2004. (World Bank Policy Research Working Paper, 3192).

CASTILHO, M. R. O acesso das exportações do Mercosul ao Mercado Europeu. Rio de Janeiro: IPEA, 2001. 53p. (Texto para Discussão, n. 851).

; SOARES, C. F. A formação do Mercosul aumentou a atratividade de IDE na região? Uma análise dos fluxos de investimentos europeus. In: WORKSHOP EM INTERNACIONALIZAÇÃO DE EMPRESAS, 5, 2005, Rio de Janeiro. Rio de Janeiro: COPPEAD/UFRJ, 2005.

CHENG, H.; WALL, H. Controlling for heterogeneity in gravity models of trade and integration. Federal Reserve Bank of St. Louis, 1999. (Working Paper, 010 E).

DASCAL, D.; MATTAS, K.; TZOUVELEKAS, V. An analysis of EU wine trade: a gravity model approach. International Advances in Economic Research, 2002.

DUNNING, J. H. Explaining changing patterns of international production: in defense of the eclectic theory. Oxford Bulletin of Economics and Statistics, Blackwell Publishing, v. 41, n. 4, p. 269-295, 1979. . Explaining international production. London: Unwin Hyman, 1988. Wesley, 1993.

. Multinational enterprises and the global economy. Reading, UK: Addison. Re-evaluating the benefits of foreign direct investment. Transnational Corporations, v. 3, n. 1, Feb. 1994.

EICHENGREEN, B.; IRWIN, D. A. The role of history in bilateral trade flows. Cambridge, MA: National Bureau of Economic Research, 1996. (NBER Working Paper, n. 5565).

EGGER, P.; PFAFFERMAYR, M. Distance, trade and FDI: a Hausman-Taylor SUR approach. Journal of Applied Econometrics, John Wiley \& Sons, Ltd., v. 19, n. 2, p. 227246, 2004.

GAULIER, G.; JEAN, S.; ÜNAL-KESENCI, D. Regionalism and the regionalization of international trade. Centre d'Études Prospectives et d'Informations Internacionales CEPII, 2004. (Working Paper, n. 16). 
GUERIN, S. The role of geography in financial and economic integration: a comparative analysis of Foreign Direct Investment, trade and portfolio investment flows. World Economy, v. 29, n. 2, p. 189-209, 2006.

HEAD, K. Gravity for beginners. 2003. Disponível em: http://strategy.sauder.ubc.ca/head//gravity.pdf. Acesso em: 20 out. 2006.

HEAD, K.; MAYER, T. Non-Europe: the magnitude and causes of market fragmentation in the EU. Weltwirtschaftliches Archiv, v. 136, n. 2, p. 285-314, 2000.

HEJAZI, W.; SAFARIAN, E. Perspectives on North American free trade. Modeling links between Canadian trade and foreign direct investment. Industry Canada Research Publications Program. University of Toronto, 1999. (Paper, n. 2).

HILLBERRY, R. Explaining the "border effect": what can we learn from disaggregated commodity flow data? Indiana University. Graduate Student Economics, Apr. 1, 1999. (Working Paper Series, 9802).

JAUMOTTE, F. Foreign Direct Investment and regional trade agreements: the market size effect revisited. International Monetary Fund, 2004. (Working Paper, n. 206).

JORGE, Carolina de Almeida. O impacto da integração comercial sobre o Investimento Direto Estrangeiro. Dissertação (Mestrado)-Universidade Federal Fluminense, Niterói, Rio de Janeiro, 28 maio 2007.

KINDLEBERGER, C. P. European integration and the international corporation. Columbia Journal of World Business, v. 1, p. 65-73, 1996.

KOSACOFF, B.; PORTA, F. La inversión extranjera directa en la industria manufacturera argentina. Tendencias y estrategias recientes. Cepal / Oficina de Buenos Aires, 1997. (Documento de Trabajo, n. 77).

KRUGMAN, P. Increasing returns, imperfect competition and the positive theory of international trade. In: ROGOFF, G.; HELPMAN, E. (Org). Handbook of international economics, 1995. v. III, 1243-1277.

LEVY-YEYATI, E.; PANIZZA, U. e STEIN, E. The cyclical nature of North-South FDI Flows. Social Science Research Network Paper, 2002.

MARKUSEN, J. R. Multinationals, multi-plant economics, and the gains from trade. Journal of International Economics, 16, p. 205-226, May1984.

MONTOUT, S.; ZITOUNA, H. Does North-South integration affect multinational firms' strategies? Review of International Economics, v. 13, n. 3, p. 485, 2005.

NEARY, J.P. Foreign Direct Investment and the single market. Paper apresentado na Conferência ETSG, 2001.

POLAK, J. J. Is APEC a natural regional trading bloc? The World Economy, p. 533-43, Sept. 1996.

SARTI, F. Internacionalização comercial e produtiva no Mercosul nos anos 90. Tese (Doutoramento)-Instituto de Economia, Universidade Estadual de Campinas - Unicamp, Campinas, 2001. 
SILVA, J. S.; TENREYRO, S. The log of gravity. Oct. 2005. (CEPR Discussion, Paper, $\mathrm{n}$. 5311).

VALLEJO, H.; AGUILAR, C. Integración regional y atracción de inversión extranjera directa: el caso de America Latina. Desarrollo y Sociedad, 0 (53), 2004.

WORLD BANK. Trade blocs. Washington: World Bank, 2000. (World Bank Policy Research Report, n. 20809).

WORLD INVESTMENT REPORT. Investment, trade and international policy Agreements. New York and Geneva: United Nations on Trade and Development, 1996. Disponível em: http://www.unctad.org. Acesso em: 18 nov. 2007.

WORLD INVESTMENT REPORT. Trends and determinants. New York and Geneva: United Nations on Trade and Development, 1998. Disponível em: http://www.unctad.org. Acesso em: 18 nov. 2007.

WORLD INVESTMENT REPORT. Transnational corporations and the infrastructure challenge. New York and Geneva: United Nations on Trade and Development, 2008. Disponível em: http://www.unctad.org. Acesso em: 10 ago. 2009.

WORLD TRADE ORGANIZATION - WTO. Régionalisme: partenaires ou rivaux? Disponível em: http://www.wto.org/french/thewto f/whatis f/tif f/bey1 f.htm. Acesso em: 16 maio 2007. 


\section{Anexo 1}

\section{Acordos comerciais regionais estudados}

\begin{tabular}{|l|l|}
\hline Siglas Acordos & Acordos \\
\hline ASEAN & Associação das Nações do Sudeste Asiático \\
\hline BAFTA & Área de Livre Comércio Báltica \\
\hline CAN & Comunidade Andina \\
\hline CEFTA & Acordo de Livre Comércio da Europa Central \\
\hline CER & Closer Economic Relations (Austrália e Nova Zelândia) \\
\hline CIS & Comunidade dos Estados Independentes (ex-URSS) \\
\hline EAEC & Comunidade Econômica Eurasiana \\
\hline EC & Comunidade Europeia \\
\hline EFTA & Associação Europeia de Livre Comércio \\
\hline Mercosul & Mercado Comum do Cone Sul \\
\hline NAFTA & Acordo Norte-Americano de Livre Comércio \\
\hline
\end{tabular}

Fonte: OMC; www.caucaz.com, ASEAN Secretariat; www.comunidadandina.org; www.mfti.gov; www.dfat.gov.au; www.uvi.gov.si.

\section{Anexo 2}

\section{Países incluídos na amostra}

\begin{tabular}{|ll|ll|ll|ll|}
\hline 1 & Albânia & 19 & Coreia do Sul & 37 & Indonésia & 55 & Polônia \\
2 & Alemanha & 20 & Croácia & 38 & Irlanda & 56 & Portugal \\
3 & Argélia & 21 & Dinamarca & 39 & Islândia & 57 & Quirguistão \\
4 & Argentina & 22 & Egito & 40 & Israel & 58 & Reino Unido \\
5 & Austrália & 23 & Equador & 41 & Itália & 59 & Rep. Checa \\
6 & Áustria & 24 & Eslovênia & 42 & Iugoslávia & 60 Rep. Eslováquia \\
7 & Bélgica; Luxemburgo & 25 & Espanha & 43 & Japão & 61 Romênia \\
8 & Bielorrússia & 26 & EUA & 44 & Letônia & 62 & Rússia \\
9 & Bósnia Herzegovina & 27 & Estônia & 45 & Lituânia & 63 & Singapura \\
10 & Brasil & 28 & Filipinas & 46 & Macedônia & 64 & Suécia \\
11 & Brunei Darussalam & 29 & Finlândia & 47 & Malásia & 65 & Suíça \\
12 & Bulgária & 30 & França & 48 & Marrocos & 66 & Taiwan \\
13 & Burkina Faso & 31 & Gabão & 49 & México & 67 & Tailândia \\
14 & Canadá & 32 & Grécia & 50 & Nigéria & 68 & Tunísia \\
15 & Cazaquistão & 33 & Holanda & 51 & Noruega & 69 & Turquia \\
16 & Chile & 34 & Hong Kong & 52 & Nova Zelândia & 70 & Ucrânia \\
17 & China & 35 & Hungria & 53 & Paquistão & 71 & Venezuela \\
18 & Colômbia & 36 & Índia & 54 & Peru & & \\
\hline
\end{tabular}

